\title{
Consulting South Africa's diverse population about the country's proposed National Water Resource Strategy
}

\author{
Vassie Maharaj* and Toni Pietersen \\ Golder Associates Africa (Pty) Ltd, PO Box 6001, Halfway House, 1685, South Africa
}

\begin{abstract}
The aim of the National Water Resource Strategy developed by the Department of Water Affairs and Forestry as the public trustee of the country's water resources, is to ensure that there is enough water of the right quality for the people of South Africa. This is to be achieved through proper use and management of water resources. The Strategy describes the ways in which South Africa's water resources will be protected, used, developed, conserved, managed and controlled. Since this may affect the way in which the various sectors of society use and value water, it is imperative that stakeholders have access to sufficient information and are provided with adequate opportunities to comment on the Strategy.

Water means different things to different stakeholders. Because of the diverse nature of the South African population, several different approaches and methods were used to consult about the National Water Resource Strategy.

The main principles of consulting the vast diversity of water users across the country included consultation with the various sectors of society both at national and Water Management Area level, building the capacity of the Department of Water Affairs and Forestry staff to conduct their own consultation meetings and consulting stakeholders according to ability. Information was made available to accommodate the different levels of education and in different formats, allowing the broadest range of stakeholders to comprehend the information and thus contribute meaningfully during the consultation process.

This multi-pronged approach to consultation resulted in many positive outcomes, which included gathering comments and issues regarding the Strategy from the broadest spectrum of the diverse South African population.
\end{abstract}

\section{Background}

The Department of Water Affairs and Forestry (DWAF) has developed a National Water Resource Strategy (NWRS) as set out in Section 5 of the National Water Act (Act 36 of 1998). This Strategy, sets out proposed strategies to achieve equity, sustainability and efficiency in the use of the country's water resources. In developing such a strategy, the Department, as the national custodian of water, together with water users, will ensure that it will be able to meet the existing and future water needs of all people especially those burdened with poverty and underdevelopment. The NWRS describes the ways in which South Africa's water resources will be protected, used, developed, conserved, managed and controlled. It outlines the Department's future plans and proposes arrangements with neighbouring countries for managing rivers shared with them.

It describes how Government will deal with water allocations, water pricing and pollution control. It outlines how the demands for water will be met in future, and the institutions that will be established to allow the public to participate in water resource management. Lastly, it deals with public safety, and how disasters such as droughts and floods will be managed and their impacts mitigated.

Because the Strategy will affect the way in which everyone in South Africa uses and values water, the Department, in line with Section (5)(b) of the Act, embarked in 2002 upon a country-wide public consultation process to bring the contents of the Strategy to the attention of water users in South Africa and to invite their comments.

This paper was originally presented at the 2004 Water Institute of South Africa (WISA) Biennial Conference, Cape Town, South Africa, 2-6 May 2004.

* To whom all correspondence should be addressed.

용+2711 2544806 ; fax:+2711 315 0317; e-mail: vmaharaj@golder.co.za
The Department appointed Manyaka Greyling Meiring (Pty) Ltd (now part of Golder Associates Africa) on 1 November 2001 to conduct the public consultation process for the development of the NWRS.

\section{Objectives}

The objectives of the NWRS public consultation process were divided into initial, intermediate and final objectives. These are listed below, also indicating the good-practice public participation principles that each set out to fulfil.

\section{Initial objectives}

- To develop the necessary capacity to comment meaningfully, therefore:

- building the capacity of Departmental personnel at its Head and Regional Offices to conduct public consultation;

- building the capacity of historically disadvantaged and other stakeholders in the water management areas (WMAs) to conduct public consultation and to contribute meaningfully (principle: capacity building and empowerment).

- To help stakeholders understand the context within which to comment (principle: accessibility of information).

- To widely announce the opportunity for comment (principle: inclusivity).

- To identify stakeholders (principle: inclusivity).

\section{Intermediate objectives}

- To allow stakeholders sufficient time and opportunity to comment (principle: efficiency).

- To consult stakeholders according to their ability (principle: accessibility of information). 
- To obtain comment from all relevant sectors of society (principle: accountability and commitment).

- To inform those who have contributed comments on the extent to which their comments could be considered in the Strategy (principle: feedback to and from stakeholders).

\section{Final objectives}

- To satisfy the legal requirement for public consultation (National Water Act (Act No 36 of 1998) Section 5).

- To test the feasibility of the Proposed NWRS in practice, to allow development of a Final (First Edition) NWRS.

\section{Public consultation process (PCP)}

As a result of the of the diverse nature of the South African population, and because water means different things to different people, several different approaches and methods were used to consult about the National Water Resource Strategy.

The main principles of consulting the vast diversity of water users across the country included consultation with the various sectors of society both at national and Water Management Area level, building the capacity of the Department of Water Affairs and Forestry staff to conduct their own consultation meetings and consulting stakeholders according to ability. Information was made available to accommodate the different levels of education and in different formats to allow the broadest range of stakeholders to comprehend the information and thus contribute meaningfully during the consultation process.

In order to reach all the stakeholders, information on the Strategy was presented verbally, visually and in writing at national level sectoral workshops and public consultation meetings/ open houses held in each of the Water Management Areas (WMAs), throughout the country. A total of 29 national level sectoral workshops and public consultation meetings/ open houses were held in different areas within each WMA, with more meetings in the larger WMAs. Thousands of issues and comments were gathered during the meetings and in writing and submitted to the Department of Water Affairs and Forestry.

This multi-pronged approach to consultation resulted in many positive outcomes, which included gathering comments and issues regarding the Strategy from the broadest spectrum of the diverse South African population. Pitching information at the correct levels contributed towards obtaining comment from a good spread of education levels. There was good geographic, race and gender representivity as well as meaningful contributions. It assisted in building relationships between the Department and its water users, water users and water users, rich and poor, developed and underdeveloped and the Department of Water Affairs and Forestry (DWAF) and other government departments. The approach also contributed to other information sharing exercises outside that of the National Water Resource Strategy. In addition, the capacity building of the Department led to better interaction between the DWAF national and regional offices, rapid understanding of the Strategy amongst departmental staff, and further information sharing sessions and meetings

\section{Public consultation methodologies}

The methodologies used in implementing the PCP during the height of the consultation activities between March 2002 and March 2003 are summarised as follows:

- Convened a national briefing session for the Department's personnel on the contents of the Proposed NWRS.
- Developed a national database of about 8400 water users, categorised geographically per Water Management Area (WMA), into sectors of society and per language preference.

- Produced and printed 120000 A4 Z-folds about the Proposed NWRS for distribution during National Water Week 2002.

- Distributed letters to announce the availability of the Proposed NWRS and invitations to participate as well as a four-page briefing document to thousands of people.

- Developed a set of power-point presentations (85 slides) on the contents of the Proposed NWRS.

- 59-page Summary of the Proposed NWRS published in the Government Gazette.

- Conducted a dry-run meeting for all Departmental personnel that would present the NWRS at Public Consultation Meetings (PCMs).

- Coordinated a schedule for the presenters and back-up presenters for the series of public consultation meetings/national workshops.

- Coordinated and administered all NWRS Steering Committee meetings.

- Distributed invitations to attend the public consultation meetings and national level sectoral workshops to thousands of water users and a 16-page Information Document in water users' language of choice.

- Distributed all versions of NWRS materials to 65 strategically selected public places countrywide.

- Developed posters for display at public consultation meetings/ national workshops.

- Announced the Proposed NWRS and series of public consultation meetings on national television's environmental programme 50/50 and on national radio.

- Coordinated regional and community radio interviews countrywide.

- Took advertisements in four national newspapers.

- Took advertisements in 28 regional newspapers covering each of the 19 WMAs.

- Distributed media releases to 150 print and electronic media countrywide.

- Distributed more than 90000 copies of NWRS related materials, electronically and on hard copy.

- Distributed more than 2000 copies of other water related materials.

- Coordinated logistics of 24 public consultation meetings and six national workshops in 19 WMAs whilst taking into account local circumstances and needs.

- Conducted 12 capacity building meetings countrywide for the Department's personnel and historically disadvantaged individuals on how to brief small groups of stakeholders and how to coordinate all logistical arrangements for public consultation meetings.

- As a result of capacity building, the Department convened 39 of its own NWRS satellite meetings countrywide.

- Built capacity of hundreds of historically disadvantaged stakeholders at the public consultation meetings and provided transport funds to these stakeholders.

- Produced 30 individual issues reports after the series of public consultation meetings and national workshops and distributed them to participants who attended for verification.

- Produced a single Comment and Response Report categorised according to the chapters of the Proposed NWRS containing thousands of comments raised by stakeholders.

- Distributed progress feedback letters to thousands of stakeholders at selected milestones. 


\section{Good practice public participation principles}

This section highlights some of the good practice public participation principles that the PCP set out to fulfil and the methods that were used to try and achieve them.

\section{Inclusive involvement of stakeholders}

The principle of inclusive involvement of stakeholders requires that all relevant stakeholders have the opportunity to be involved, recognising that it is not practically possible to consult every individual but emphasising the importance of affording a broad range of stakeholders the opportunity to be heard. Further, the principle requires representation in terms of race, gender, age, cultural group and demographics, and that no group dominate the outcome of the process.

\section{All relevant stakeholders have opportunity to be involved}

Recognising the importance of affording a broad range of stakeholders the opportunity to be heard, the PCP:

- Established a direct mailing list (using an electronic database) of over 8400 individuals and organisations country-wide that received invitations and announcements addressed to them personally.

- Used local, regional and national print, broadcast and television media to announce the opportunity to become involved.

- Appealed to stakeholder organisations nationally to assist in distribution of documents.

- Prominently displayed documents in public places and the Department of Water Affairs and Forestry offices countrywide.

- Making documents available to delegates at relevant conferences.

\section{Stakeholder database}

The database was established as follows:

- Telephonic networking and referral, with direct contact with stakeholders in the language of their choice.

- Obtaining and verifying stakeholder mailing lists provided by stakeholder organisations (e.g., Catchment Forums already established), Departmental Regional and National Offices, Departmental service providers and so forth.

- Undertaking a gap analysis through categorising stakeholders geographically and into sectors of water users. Where gaps were detected either in sectors of society or per WMA, these were filled through networking and referral and consultation with the Department of Water Affairs and Forestry Regional Offices.

- Adding stakeholders that:

- responded to media articles, radio announcements and advertisements

- responded to information on the Department's Web site

- responded to information left in public places and at the Department of Water Affairs and Forestry Regional Offices country-wide

- $\quad$ were suggested by their organisations, colleagues or friends in response to a reply sheet that accompanied the first announcement of the opportunity to become involved, and in response to A5 cards distributed at the series of public consultation meetings.

The 8400 stakeholders on the database were categorised as follows:
- Geographically into 19 Water Management Areas (WMAs)

- According to 25 sectors of society or sectors of water users

- Key stakeholders (people who stand to be directly affected, influential people, respected people, spokespeople for their sectors, people with the authority to say "yes" or "no," people whose local knowledge is important, people who may want to derail the process for personal gain, and all those who think they are key stakeholders)

- $\quad$ Language preference.

\section{Representation in terms of sectors of society or sectors of water users}

An analysis of the database, attendance at meetings, number of issues raised and race and gender representivity showed that local government comprised the biggest portion (14\%) of the database. Other large sectors were closely grouped in terms of percentages, i.e. CBOs and NGOs (10\%), agriculture (8\%), residents/individuals (8\%), members of water forums and water institutions (each $7 \%$ ) and mining and industry (6\%), reflecting a fairly even spread of sectors of water users.

\section{Representation in terms of race, gender, age, cultural group and demographics}

The following special efforts were made to ensure proper representation by race of a truly South African society:

- active mobilisation by the PCP office of grassroots and local communities and other stakeholder organisations to become involved in the process.

- making available funding for transport and in some cases also arranging the transport.

- having documents available in 11 languages.

- advising such organisations in advance that local languages would be spoken at public consultation meetings.

\section{Mutual respect: acknowledge and respect each others' knowledge, abilities and inputs}

This principle is fundamental to satisfying the process objectives of any public participation process. Achieving it establishes trust and credibility for the process and leads to constructive contributions and creative new solutions. The Department of Water Affairs and Forestry personnel that interacted with stakeholders at the various meetings were assisted to understand, appreciate and implement this principle.

This principle is also applicable among stakeholders, including those that traditionally may have been in conflict, opposition or political strive. For this reason, the PCP team's facilitators opened each meeting with guidelines for productive discussion, obtaining agreement of those present to conduct the meeting in the spirit of these guidelines.

These guidelines were:

- Focus on the issue, not the person (i.e. do not become personal).

- Be courteous towards others at all times.

- Only one person should speak at a time.

- Work through the facilitator to ensure that everyone gets a fair chance to speak.

- Agree to disagree, since it is diversity of opinion that ultimately enriches decision-making.

In addition, the PCP facilitators had strong facilitation skills to prevent unhealthy conflict at meetings, coupled with empathy for any stakeholder contribution, and never being judgemental or disrespectful in handling a stakeholder comment at a meeting. 
Commitment to enable people to express their views

The Department of Water Affairs and Forestry's commitment to enable people to express their views is clearly illustrated by the department's willingness to set aside a substantial budget for stakeholder capacity building and awareness creation.

Stakeholders expressed satisfaction for the opportunity to contribute their views and commended the Department for the professional manner in which the public consultation meetings/ national workshops were conducted to bring about mutual respect.

\section{Respect for cultural diversity and language preference}

South Africa is truly a rainbow nation of cultures and languages.

The NWRS PCP respected cultural and language diversity in several ways:

- Members of the PCP and the Department of Water Affairs and Forestry teams in attendance at meetings with stakeholders spoke the local languages and understood local customs and cultures. Team members included facilitators, secretariat teams, scribes, people briefing small groups of stakeholders during the open house component, support staff and others.

- The NWRS Information Document Using Water Wisely was available in 11 languages.

- Stakeholders at meetings were encouraged to speak in their language of choice at meetings.

- Catering for vegetarians, religious groups (e.g. halaal) and local groups (pap en vleis).

- Where required, meetings were opened and closed with prayers.

- The Department of Water Affairs and Forestry staff that presented the contents of the strategy were, as far as possible, locally based, speaking local languages, making presentations in local languages where required, and in some instances wearing traditional dress.

\section{Many opportunities to contribute}

The PCP was designed so as to provide ample opportunity for stakeholders to comment, exchange information and share and evaluate views.

This was done as follows:

- All documentation, including letters, distributed to stakeholders were accompanied by comment sheets inviting written/verbal comment in stakeholders' language of choice.

- All media advertisements and releases invited verbal/written comment.

- Participants at all public consultation meetings, national workshops, satellite meetings and individual briefing meetings were encouraged to raise issues and comments, to share local knowledge and evaluate views.

- Participation by stakeholders took place in successive rounds so as to build up their information base and their understanding of issues.

- Many stakeholders arranged their own sector-specific meetings and presented copies of the Department of Water Affairs and Forestry presentations to their constituencies so as to share information, views and provide additional opportunities for comment.

\section{Consideration of multiple options}

The principle of multiple options supports stakeholders to consider various alternatives. Particular initiatives may generate many options, all of which should be considered, including the option of no development. Alternatives to the option/s provided by the Department of Water Affairs may be identified through suggestions produced by local knowledge. Independent facilitation makes it easier to raise issues and multiple options.

\section{Support to stakeholders to consider various alternatives}

A proposed NWRS was widely made available for stakeholder comment, which included the option of contributing alternatives. This was done in the following ways:

- Comment Sheets accompanied all Proposed NWRS documents for stakeholders' comments, issues of concern and proposed alternatives.

- Providing stakeholders with opportunities to state their views verbally at the various public consultation meetings, national workshops and satellite meetings.

\section{Independent facilitation}

A key success factor of the PCP was the independent facilitation that consistently took place during the course of the PCP countrywide at all the meetings and workshops. Independent facilitation made it easier for stakeholders to raise issues and multiple options.

The facilitators achieved this by:

- Encouraging stakeholders at the public consultation meetings and workshops to raise issues of concern and to contribute constructive inputs.

- Comforting stakeholders that suggestions produced by local knowledge would enrich the contents of the Final NWRS, which ultimately was aimed at sustainable development (inclusion of local and traditional knowledge).

\section{Flexibility}

The principle of flexibility refers to the need for public participation processes to adapt to different circumstances. Local social dynamics and diversity should be understood and respected.

A key aspect in which flexibility manifested was in language and meal preference, as well as in stakeholders' venue preferences, consulting stakeholders according to ability etc.

\section{Success of previous processes}

The PCP design was based on the success and lessons learned from previous national consultation processes.

In previous policy processes the following key success factors became clear:

- Visible political commitment from national government

- Management of stakeholders' fears and expectations

One of the guiding principles in the NWRS PCP was to give the Department, in particular, Minister Kasrils prominence. News releases quoting the Minister were distributed, clearly illustrating the Department's commitment. In addition, each public consultation meeting was opened by a Senior Departmental Official, in some cases the Director General or Deputy Director General, publicly committing the Department to the process.

Needless to say, it is easy to create undue fears and expectations. Historically disadvantaged people living in poverty had expectations of an immediate higher quality of life, e.g., that they would receive water in areas where access to water was still a problem. On the other hand, the PCP had to manage stakeholders' fears, e.g., irrigation farmers who will have to pay higher water tariffs feared that it would no longer be economically feasible to grow certain crops. Other sectors such as the mining and industry 
sectors were concerned about the waste discharge charges proposed to be implemented by the Strategy and how that would affect their bottom line.

These fears and expectations were allayed by providing sufficient information to stakeholders, whilst making it clear to stakeholders that the accountability for decisions and the final decisions rested with the Department and, in certain cases, the Minister of Water Affairs and Forestry. The Department of Water Affairs and Forestry also continuously conveyed the message that stakeholders' contributions would lead to informed and enriched decision-making.

\section{Degree of stakeholder trust in decision-makers}

Based on previous experience and information discussions with the Department of Water Affairs and Forestry, it was known from the outset that certain sectors of society were extremely concerned about water resource management in South Africa, e.g., the agriculture and forestry sectors. Their concerns were principally focused on the availability of water for their enterprises and/or water use changes. Similarly, the mining, industrial, power generation, chemical processing and waste management sectors, and in particular with changing environmental legislation affecting them and global pressure on them to develop sustainably, were concerned about a range of factors including water use charges, administrative delays in licence applications and the capacity of the Department to implement new policy. For these reasons the PCP included sectorspecific workshops for each of these sectors individually and made special efforts to ensure that they attended and had personal contact with the Department's personnel countrywide.

\section{Level of empowerment of different sectors}

The huge diversity in education levels (ranging from people with dual-doctorates to those with a basic education) at some public consultation meetings presented challenging situations to both the facilitators and the Department's presenters. A key component of the PCP was to build the capacity of historically disadvantaged stakeholders as well as the Department of Water Affairs and Forestry staff in the different WMAs.

To achieve this, the PCP team did the following:

- Convened 12 capacity building meetings for the Department's staff at the Head and Regional Offices to assist in building the capacity of stakeholders to contribute.

- Combined the public consultation meetings with an open house component, where materials and the contents of the Proposed Strategy were graphically presented and visually displayed. Stakeholders could attend the open house two hours prior to the start of the public meeting to obtain more information about the Strategy in small groups or individually in their language of choice. This enabled meaningful contributions during and after the meetings.

\section{Degree to which sectors are organised and represented}

Care was taken throughout the PCP to involve all sectors of society. In many cases PCP community facilitators established how certain sectors were organised and assisted especially previously disadvantaged communities that were not organised to attend meetings.

\section{Transparency}

The principle of transparency refers to the honest, open and equitable nature of public participation. Productive relationships between civil society and government require that role players should be transparent, efficient and equitable and that participants act with integrity.

\section{Stakeholders to be transparent, efficient, equitable and act with integrity}

The PCP's independent facilitators encouraged transparent, efficient and equitable participation by opening each public meeting and national workshop with guidelines for productive discussion. All stakeholders unanimously agreed to these guidelines at all the public consultation meetings and workshops convened countrywide.

\section{Objectives and scope of process to be made clear at the start}

Stakeholders received information from the beginning and during the course of the PCP on the objectives and scope of the process and how and when they could participate, as follows:

- Every Proposed NWRS document produced indicated the opportunity for verbal and written contributions, e.g., the Information Document Using Water Wisely.

- $\quad$ Paid media advertisements.

- Media releases to printed and electronic media.

\section{Transparency and honesty about impacts on, and benefits to stakeholders}

The Department of Water Affairs and Forestry conveyed farreaching implications of the Proposed Strategy to stakeholders honestly and openly, e.g. information about current and future water availability in each WMA was shared. All NWRS documents covered the benefits of the Proposed Strategy to stakeholders, e.g., poverty alleviation through water, while potential impacts to certain sectors of stakeholders were not avoided, e.g., water pricing.

During the PCP participants' written and verbal comments were captured in individual Issues Reports after each public meeting and national workshop. These reports were mailed to them to verify that their comments were captured correctly. In some cases stakeholders made corrections, which were incorporated. A single Comment and Response Report was produced. The Department of Water Affairs and Forestry is in the process of formulating responses to the numerous comments.

\section{Accountability and commitment}

The principle of accountability and commitment stresses that role players should be encouraged to take responsibility for the process of public participation. There should be shared responsibility and accountability between role players in terms of commitments, burdens, benefits, successes and failures of the process. The Department of Water Affairs and Forestry should commit itself visibly and publicly to each participation process. The Department of Water Affairs and Forestry officials should be well informed and able to answer questions clearly and efficiently. The process design should enable marginalised and disadvantaged groups to commit their time and resources to the process. Participants representing sectors should take responsibility for familiarising themselves with documentation for discussions, submitting comments by target dates and active participation in meetings that add value to decision-making.

Many participants familiarised themselves with the contents of the Proposed Strategy prior to the meetings or workshops and in cases where this was not possible, many arrived earlier to avail themselves of the contents of the Strategy. Many also attended public consultation meetings or national workshops and in cases 
where they could not personally attend meetings, they sent representatives.

\section{Accessibility of information}

The principle of accessibility of information enables effective participation by supporting stakeholders to be well informed and knowledgeable. Stakeholders should have timely access to information to participate effectively. The information should be accessible in terms of language and terminology in order to build the capacity, understanding and knowledge of stakeholders. Materials should be easily obtainable and stakeholders should be supported in distributing it to their constituencies. Information on which decisions are based should be detailed, accurate, easy to understand and cover all relevant aspects of the issues. Participation should be in accordance with the ability and interest level of stakeholders.

\section{Timely access to information}

Care was taken at the design phase of the PCP to ensure that stakeholders receive timely access to information.

This was done in the following ways:

- A flyer introducing the Proposed NWRS and forthcoming PCP was prepared and distributed countrywide during National Water Week 2002.

- A Briefing Document explaining the legal context of policy, law and the NWRS was prepared and proactively distributed to stakeholders countrywide. It mentioned the next steps in the PCP.

- An Information Document Using Water Wisely containing information about the dates and venues as well as places where information could be accessed was distributed to stakeholders approximately eight weeks prior to the start of the first public meeting and national workshop.

- Paid media advertisements containing similar information were published in national and regional papers.

- Media releases were distributed to print and electronic media countrywide, e.g., the national television programme 50/50 broadcast the availability of the Proposed Strategy and the places of access to information.

\section{Information accessible in terms of language and terminology}

One of the key principles of the NWRS PCP was to consult people according to their ability. Information produced during the NWRS PCP was accessible in two ways, i.e:

- The Proposed NWRS was available to stakeholders in various versions, as follows:

- Full Proposed NWRS ( 275 pages)

- Summary Proposed NWRS ( 59 pages) published in the Government Gazette

- A simplified, illustrative 16-page Information Document Using Water Wisely was available in all 11 South African languages (see Figure 8 earlier on stakeholders' satisfaction with languages used) and mainly targeted at stakeholders with basic education levels.

- Terminology was explained during capacity building meetings, public consultation meetings and open houses.

- Care was taken to become familiar with stakeholders' level of knowledge before the meetings started, e.g., the principle at the public consultation meetings was to assist communities in their own WMA to attend the public consultation meeting(s) in their own areas, especially to get a better understanding of the water situation in their WMAs. However, water users were welcome to attend public consultation meetings in other WMAs and many did so.

\section{Materials easily obtainable}

The PCP Office distributed thousands of copies of NWRS materials proactively via electronic and normal mail. In addition stakeholders could access all NWRS documentation at:

- $\quad$ selected public places countrywide

- public consultation meetings/national workshops

- the Department's web site.

\section{Awareness creation}

The principle of awareness creation refers to the need to make stakeholders aware of issues affecting them and how they might influence the outcomes of the process. Officials should clearly and truthfully articulate all relevant policy, plan and programme issues at the beginning of a process in order to make people aware of how they are affected. The opportunity to participate should be announced in ways that are appropriate for that sector. This should be undertaken over a period of time to ensure that the broadest spectrum of stakeholders is aware of the opportunities to participate (DWAF, 2001).

\section{Create awareness at the beginning of the process}

From the onset of the NWRS PCP stakeholders were made aware of the availability of the Proposed Strategy, its contents and the potential impacts and benefits of the NWRS on stakeholders.

\section{Announcement of opportunity to participate}

Methods to announce the opportunity to participate took into consideration the needs of the spectrum of society, i.e. those who are highly qualified in terms of education and those who are illiterate, e.g., visual and print material, announcements of the project on national television and radio, interviews on national, regional and community radio and paid adverts in national and regional newspapers.

In addition, thousands of documents were distributed countrywide to different sectors of society via electronic forwarding, on $\mathrm{CD}$, via mail and at various public consultation meetings, national workshops, satellite meetings convened by the Department's regional offices and meetings convened by stakeholder organisations, tribal leaders etc.

The following media liaison approach was applied as one of the tools to encourage countrywide participation.

- Making use of countrywide paid advertisements, i.e. by taking advertisements in four national and 28 regional newspapers.

- Distributing media releases countrywide to print media to inform stakeholders about the meetings and their venues.

- Distributing media releases countrywide to electronic media and arranging radio interviews with the Department of Water Affairs and Forestry officials in various WMAs to announce the dates and venues of the public consultation meetings and provide information on the Proposed Strategy.

- National television's popular environmental programme 50/50 broadcast the availability of the Proposed NWRS and opportunity for participation.

\section{Capacity building and empowerment}

The principle of capacity building and empowerment requires that all stakeholders be granted both the opportunity and support to participate meaningfully. Public participation empowers 
stakeholders because it offers them the opportunity to develop the knowledge, skills and resources necessary to control their own lives and operations. Informed and empowered stakeholders contribute effectively and on an equal basis. Special efforts to build the capacity of previously disadvantaged communities to collect and disseminate information and undertake internal consultation should be one of the first steps of the public participation process. These marginalised groups possess special local knowledge and understand their own situation best.

\section{Offering the opportunity to develop knowledge, skills and resources of historically disadvantaged stakeholders}

One of the initial objectives of the NWRS PCP was to develop the necessary capacity for stakeholders, in particular historically disadvantaged individuals/organisations, to comment meaningfully.

This was done as follows:

- Historically disadvantaged stakeholders had an opportunity to attend open houses where key concepts of the Proposed NWRS were explained to them in their language of choice.

- Where necessary, the Department provided these stakeholders with funds for transport.

- Stakeholders were supplied with take-away copies of materials that dealt with the NWRS as well as other water-related material, e.g., "Some for all forever".

- Stakeholders had an opportunity to request copies of the reference materials that were on display by completing a request form.

\section{Building the capacity of the Department of Water Affairs and Forestry officials}

A key component of the NWRS PCP was to build the capacity of the Department of Water Affairs and Forestry officials at the Head and Regional Offices.

This was done as follows:

- A total of 11 capacity building meetings took place countrywide.

- These meetings generally took place one day in advance of the public consultation meetings and each participating Department of Water Affairs and Forestry staff member received a set of guidelines and training on:

- how to convene small group briefing meetings

- $\quad$ how to approach stakeholders and how to address them

- how to set up a venue

- how to register stakeholders at a meeting.

- The Department of Water Affairs and Forestry staff had an opportunity to role-play real meeting situations to prepare them for different types of situations, questions that may occur and to ensure that the messages conveyed by them were consistent.

- In many cases the Department of Water Affairs and Forestry presenters also attended these sessions and were assisted with their presentations, their presentation style and how to deal with different questions.

\section{Providing an opportunity to verify that issues were considered}

A key component of any public consultation process is the provision of various opportunities to stakeholders to verify that the issues and/or concerns raised were captured and considered.

In the NWRS PCP this was done as follows:

- The facilitators often reflected participants' issues back at the public consultation meetings and national workshops to ensure that the issues were understood.
- Participants' were informed at the meetings and workshops that their issues were being captured during the meeting, and that they were welcome to contribute more issues during tea and lunch times, before and after the meetings.

- All participants and those who requested copies (e.g., those who could not attend the meetings) received an Issues Report of the issues raised at the meeting(s) they attended to verify that the issues were captured correctly. Note that all comments submitted in writing at the meetings and workshops were also captured as part of the Issues Report. Some participants made changes, all of which were incorporated.

- All written comments submitted during the course of the PCP were captured in a single Comment and Response Report.

As the Department is still in the process of formulating responses whilst incorporating the comments into the First Edition NWRS, stakeholders have not yet been informed on the extent to which their comments were considered. The Department reports that reasons will be provided for the inclusion and/or exclusion of comments in the Comment and Response Report.

\section{Key outcomes}

The key outcomes of the NWRS PCP are as follows:

- More than 2300 comments, categorised per chapter of the Proposed Strategy, by commentator, per WMA and response, received from 600 stakeholders representing different sectors of society.

- The issues and comments raised on the Proposed NWRS enriched its content and the breadth of thinking.

- Large scale information transfer took place throughout South Africa, educating in particular historically disadvantaged individuals/organisations with regard to the country's current and future water situation, water conservation and so on.

- The NWRS PCP was pitched at the right level, because of participation by stakeholders representing vastly different education levels, different geographic areas, different racial groups and gender and because of the good quality of comments and meaningful contributions received.

- The NWRS PCP enhanced relationships between the Department and its water users, between fellow stakeholders, between rich and poor, developed and underdeveloped, between the Department and other government departments (cooperative governance) and internally between its Head and Regional Offices.

- There was massive information sharing that extended beyond the NWRS and that had a ripple effect throughout the country among constituents of various sectors of society.

- Success in building the Department's capacity on how to convene public consultation meetings. The capacity building sessions resulted in more interaction between the Department's Head and Regional Offices, in shared lessons learnt throughout the NWRS PCP, a rapid understanding of the new Proposed Strategy by personnel on all levels of the Department, communication with stakeholders by the Department's staff, convening 39 of its own satellite meetings in different WMAs and further information sharing sessions with stakeholders.

- A stakeholder list for the Department comprising more than 8 400 stakeholders, categorised into sectors of society, geographically in 19 WMAs, according to languages and key stakeholders.

- Content stakeholders who commended the Department on convening in an open and transparent way a series of successful 
meetings during which facilitation, presentation of information, languages used and accessibility to documents were masterfully dealt with.

- The NWRS PCP laid the foundation for continuing dialogue beyond the completion of the First Edition NWRS and entering into new dialogue countrywide upon implementation of the NWRS.

\section{Conclusion}

As one of the Department's flagship programmes - the First Edition NWRS will be living proof of how effective integration of technical content and people's comments can be done to enrich decisionmaking. The NWRS PCP has paved the road in many ways already described for successful, integrated and co-operative implementation of not only the Final (First Edition) NWRS, but also of future government-driven projects. 